\title{
Modos de representación literaria de la zona gris. Una lectura de dos novelas chilenas
}

Hans Lauge Hansen

Universidad de Aarbus

\begin{abstract}
Resumen:
Este artículo realiza una lectura de dos novelas chilenas, El desierto de Carlos Franz (2005) y La vida doble de Arturo Fontaine (2010). Ambas novelas aplican la perspectiva del victimario en la represión violenta de la izquierda política después del golpe de estado de Augusto Pinochet en 1973, pero de forma muy diferente. El artículo contextualiza las dos novelas en relación a un 'giro victimario' internacional y la subsiguiente desconstrucción de los patrones narrativos utilizados para representar un pasado violento, y propone un enfoque modal en el análisis comparativo de las dos novelas. El concepto de la "banalidad del mal" de Hannah Arendt y las dos diferentes versiones descritas por Maria Torgovnick, "Eichmann está en todos nosotros" y "todos podríamos ser Eichmann", se aplicarán para describir las diferentes formas con que las novelas conceptualizan y contextualizan las categorías morales.
\end{abstract}

Palabras clave: memoria cultural, Chile, zona gris, victimarios, deconstrucción narrativa, memoria agonista

\begin{abstract}
:
This article engages with a comparative reading of two contemporary Chilean novels, El desierto by Carlos Franz (The desert, 2005) and La vida doble by Arturo Fontaine (The double life, 2010). Both novels include the perspective of a perpetrator in the violent suppression of the political Left following Augusto Pinochet's coup d'etat in 1973, but they do so in very different ways. The article contextualizes the novels in relation to a broader, international 'perpetrator turn' and the subsequent deconstruction of hegemonic narrative templates used in the representation of the conflicts of the past, and proposes to apply a modal approach to the analysis of the differences between the novels. Hannah Arendt's concept of the "banality of evil" and Maria Torgovnick's interpretation of its different possible applications, "Eichmann is in all of us" and "Anyone could be Eichmann", are used to describe the different ways in which the two novels engage with moral categories and social contextualization of 'evil'.
\end{abstract}

Keywords: cultural memory, Chile, grey zone, perpetrators, narrative deconstruction, agonistic memory

\section{Introducción}

Desde el cambio de milenio se puede registrar en buena parte del mundo occidental (Europa y los EEUU) un crecimiento en la cantidad de productos culturales que focalizan la memoria de un pasado violento ya no desde el punto de vista exclusiva de la víctima, sino también desde el del victimario y de personajes pertenecientes a esta zona oscura entre víctimas y victimarios que Primo Levi llamaba la zona gris: colaboradores, delatores, traidores y cómplices (Crownshaw; Eaglestone). No se trata de aplicar una 
perspectiva exclusiva a la historia del pasado violento, ni una perspectiva solidaria que excusara o legitimara las atrocidades cometidas, sino una perspectiva críticamente perfilada a través de otros enfoques, sea el de un narrador implícito en novelas, la voz en off en documentales, o mediante una focalización multiperspectivista que hace contrastar esta perspectiva con la de las víctimas. Ejemplos podrían ser la novela Las benévolas (Les Bienveillantes, 2006) de Jonathan Littell, la serie televisiva alemana Unsere Mütter, unsere Väter, el documental Das radikal Böse, o la obra biográfica de Åsne Seierstandt sobre el asesino noruego Breivik, Uno entre nosotros (2015). Estos ejemplos son todos sacados de un contexto europeo, y es importante notar que la perspectiva del victimario parece ser mucho menos extendida en las obras artísticas que encontramos dentro del contexto de las culturas hispanohablantes. Tanto en España como en América Latina sigue predominando la perspectiva de la víctima en los discursos sobre el pasado. Se pueden, desde luego, registrar importantes excepciones como, por ejemplo Nocturno de Chile de Roberto Bolaño (2000) en Chile, Fin de la bistoria de Liliana Heker (1996) en Argentina y El hombre que amaba a los perros de Leonardo Padura (2009). En España sólo se han publicado unas pocas novelas como La noche del diablo de Miguel Dalmau (2008) y Twist de Harkaitz Kano (2013) antes del 2016, pero en 2017 salieron en la misma vena El monarca de las sombras (Javier Cercas), Banderas en la niebla (Javier Reverte) y Perros que duermen (Juan Madrid). En otras palabras, hay indicios de que la tendencia en boga en Europa Central y los EEUU también empieza a tener un impacto en las culturas hispanohablantes.

Lo que une a estas obras es el interés por comprender lo que pueda llevar a una persona a convertirse en lo que en una época posterior se considera como el culpable de crímenes de lesa humanidad. No se trata de excusar ni legitimar, sino de comprender. Como dice Primo Levi a los alemanes que sobrevivieron la segunda guerra mundial: "Necesito comprenderte para poder juzgarte" (Levi 174, traducción mía). Pero el modo ético-político con que estas obras se acercan al pasado y explican el proceso de conversión de un ser humano a lo contrario de lo que era antes, puede variar, y nos hacen falta criterios teóricos para analizar. En este artículo propongo entender este fenómeno transnacional como un cambio de paradigma narrativo y quiero proponer un modelo teórico de análisis para comprobarlo, basándome en la lectura de dos novelas chilenas. Como tal, el artículo no ofrece en sí un análisis comparativo transatlántico, sino presenta algunas reflexiones sobre cómo abordar el análisis de este fenómeno literario transnacional.

\section{Presupuestos teóricos}

Es un presupuesto teórico del artículo que existen patrones narrativos transnacionales sobre los conflictos del pasado que informan los relatos locales en el sentido de que combinan determinadas formas de narrar con determinados modos ético-políticos de distinguir entre lo malo y lo bueno y de distribuir las relaciones entre crimen y justicia, entre culpa y perdón. Las narraciones de la alta modernidad contrapusieron de un modo antagonístico la figura del héroe, personaje a menudo joven, guapo y tan bueno como el pan, al villano malintencionado y de carácter inmoral. La violencia cometida 
por el héroe se considera buena o al menos perdonable porque está hecha para delimitar el mal que representa el villano. Un ejemplo a mencionar podría ser Por quién doblan las campanas de Hemingway.

Este patrón narrativo fue paulatinamente sustituido durante los años ochenta y noventa por otro patrón narrativo que, con una expresión de Daniel Levy y Natan Sznaider, podemos llamar el modo cosmopolita de hacer memoria (Levy y Sznaider, "Memory Unbound"; Levy y Sznaider, The Holocaust and Memory). El patrón narrativo de la memoria cosmopolita encuentra su fundamento en las narraciones de la memoria del Holocausto, desarrolladas en diálogo con las teorías postestructuralistas en boga por aquella época. La memoria del Holocausto tomó como punto de vista el sufrimiento de las víctimas de la violencia y la represión. El elemento digamos 'invisible' en el conflicto entre los actores del patrón antagonístico, el protagonista, o el héroe, y el antagonista, o el villano, es la figura de la víctima no beligerante e inocente. La invisibilidad de la figura de la víctima en el modo antagonístico nos permite interpretar el interés prestado por el sufrimiento de la víctima en los discursos de la memoria del Holocausto como una deconstrucción, al transponer la tensión dramática entre héroe (agente activo valorado de forma positiva como 'bueno') y villano (también agente activo, pero valorado de forma negativa como 'malo') a la relación entre la víctima (agente valorado de forma positiva) y la figura que emerge como figura de trasfondo: el victimario o perpetrador (agente activo valorado de forma negativa).

Figura 1:

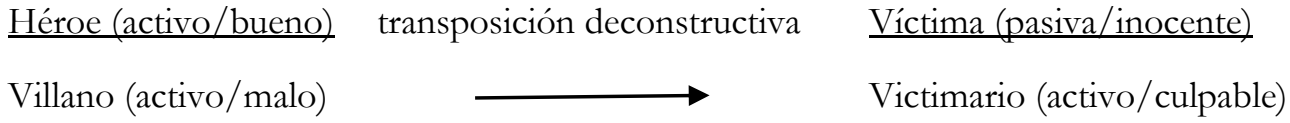

La sustitución del modo antagonístico por el modo cosmopolita no ha sido ni exhaustiva ni total, porque en discursos políticos del neo-nacionalismo y en la cultura popular todavía podemos notar una presencia importante del modo antagonístico de hacer memoria, e incluso un aumento. Pero entre las obras con ambición artística sí podemos notar un desarrollo significante desde un paradigma a otro. Contrastando los dos modos podemos notar que los conceptos morales (lo bueno y lo malo), se aplican de forma diferente según los dos patrones narrativos. Si en el modo antagonístico las nociones morales se aplican directamente a los actantes (protagonista, antagonista, ayudante y opositor), y a través de ellos a los personajes que desempeñan estas funciones (este personaje actúa como actúa porque es malo), las categorías morales se aplican según el modo cosmopolita a entidades abstractas como regímenes totalitarios o sistemas democráticos. Eso nos permite reconocer a un personaje como siendo en principio bueno, pero forzado a hacer 'cosas malas' porque pertenece a un sistema que se sostiene en la opresión y la violencia. Un ejemplo podría ser el protagonista en la película Das Leben der Anderen (2006). El resultado de esta primera deconstrucción del patrón narrativo resulta ser la aplicación de una perspectiva individual y despolitizada (Cento Bull y Hansen), que contribuye a la universalización de los valores de los derechos humanos que a su vez fomentó al cosmopolitismo político (Levy y Sznaider). 
La segunda hipótesis teórica de este artículo es que la perspectiva del victimario o de personas pertenecientes a esta ambigua zona que Primo Levi llamaba "la zona gris" (Levi 42) se puede entender como una deconstrucción de segundo grado del patrón narrativo en el sentido de que es una deconstrucción de la primera deconstrucción hecha por la perspectiva narrativa del patrón de la memoria cosmopolita. El actante invisible en el conflicto entre víctimas y victimarios consiste de gente de esa zona gris, donde las víctimas también son victimarios, y donde la distinción entre las categorías morales se complican y se deconstruyen. Esta deconstrucción de segundo grado puede realizarse por una transposición de la perspectiva narrativa de la víctima al actante invisible o por una simple inversión de la perspectiva en la relación entre víctimas y victimarios.

\section{Figura 2:}

$\begin{array}{lcl}\text { Víctima (pasiva/inocente) } & \text { inversión deconstructiva } & \underline{\text { Victimario }} \\ \text { Victimario (activo/culpable) } & \longrightarrow & \text { Víctima }\end{array}$

Este modelo no es, desde luego, exacto, porque oculta que la deconstrucción de segundo grado tiende a borrar el sentido diferenciador entre las mismas nociones de la víctima inocente y el verdugo culpable, y busca en cambio indagar en las condiciones que permiten el desarrollo violento sin aplicar categorías morales (inocente/culpable, bueno/malo).

En su análisis del proceso contra Eichmann, Hannah Arendt demostró que Eichmann no era un monstruo, sino una persona "terriblemente normal" y un producto de su tiempo y del régimen que le tocó vivir. Arendt acuñó — basándose en este hechosu concepto de la banalidad del mal. En su libro War Complex: World War II in Our Time María Torgovnick afirma que este concepto en muchas ocasiones ha sido malinterpretado, y propone distinguir entre dos diferentes modalidades en la interpretación del mismo concepto (Torgovnick 63-69): "Eichmann está dentro de todos nosotros" por un lado, y "Todos podríamos ser Eichmann” por otro. Según la primera modalidad tenemos como seres humanos disposiciones ético-morales hacia la bondad y hacia el mal como fuerzas opuestas interiores, con lo cual la relación entre lo bueno y lo malo queda universalizada y relegada a una cuestión existencialmente moral e individual. Según "Todos podríamos ser Eichmann", en cambio, son principalmente las circunstancias políticas y sociales de una sociedad particular las que determinan si personas mentalmente sanas y normales quedan enrolladas como responsables en la ejecución de atrocidades de escala mayor.

Para vincular esta distinción entre dos maneras de representar a los victimarios y personajes de la zona gris a una teoría de envergadura más amplia, propongo tomar en cuenta la manera en que Cento Bull y Hansen describen las diferencias entre tres modos ético-políticos básicos que podemos encontrar en los discursos de memoria de un pasado violento (Cento Bull y Lauge Hansen). Según esta teoría se puede distinguir entre el modo antagonista, el modo cosmopolita y el modo agonista de hacer memoria. El modo antagonista defiende una versión de la historia frente a otra y se corresponde con el tipo de narración que distribuye los conceptos morales, lo bueno y lo malo, 
directamente entre los actantes de una trama en la que el antagonista se representa como moralmente inferior. Es una modalidad ético-política que está ideológicamente comprometida con una posición determinada y que no puede incluir diferentes voces o puntos de vista, ni ninguna forma de auto-reflexión. En cambio, tanto el modo cosmopolita como el modo agonista son modalidades más reflexivas y auto-reflexivas que permiten incluir múltiples perspectivas, pero se diferencian entre sí por el uso de las categorías morales y por la inclusión de las voces y perspectivas. El modo cosmopolita se caracteriza por elevar la perspectiva de la víctima al centro de atención para despertar compasión, y tiende a vincular los conceptos morales con sistemas abstractos como regímenes autoritarios y sistemas democráticos. Esta finalidad o afán de despertar compasión a través de una condena moral afecta a la diversidad de las voces incluidas, ya que normalmente sólo se incluyen las voces de las víctimas y sus simpatizantes, y repercute en la medida en que el discurso memorialista indaga en los conflictos políticos que en un primer momento despertó la violencia (Gómez López-Quiñones). Finalmente, el modo agonista de hacer memoria resiste la aplicación de las categorías morales e insiste en comprender las motivaciones de los sujetos para actuar como actuaron. No se trata de disculpar ni de legitimar la represión ni la violencia, sino de comprender los procesos que llevan a personas normales a cometer atrocidades. El modo agonista insiste por lo tanto en la descripción de los conflictos sociales y políticos del pasado que en un primer momento engendraron la violencia y, a través de ella, en la repolitización de la relación entre el presente y aquel pasado. Debido al afán de comprensión de los motivos tanto de uno como de otro lado del conflicto, el modo agonista incluye en la absoluta mayoría de los casos las voces de los victimarios.

Tomando como punto de partida esta división teórica de los modos ético-políticos, insistimos en que la modalidad "Eichmann está dentro de todos nosotros" se corresponde con el modo cosmopolita por sus efectos moralistas y despolitizantes; es la forma en que el modo cosmopolita puede incluir la perspectiva del victimario. En cambio la modalidad "Todos podríamos ser Eichmann" se integra en el modo agonista debido al énfasis que pone en la comprensión de las condiciones políticas y sociales que en gran medida determinan los actos de los personajes. A continuación vamos a ver cómo dos novelas chilenas, El desierto de Carlos Franz y La doble vida de Arturo Fontaine, describen los procesos que llevan a gente normal a ser o sentirse culpables de crímenes de lesa humanidad. Asimismo, examinaremos cómo podemos usar las distinciones propuestas por Torgovnick y Cento Bull/Hansen para interpretar el modo ético-político con que cada una de las dos novelas se acerca al pasado violento.

\section{Carlos Franz: El desierto (2005)}

La novela El desierto de Carlos Franz ha sido denominada como la gran novela total de la dictadura chilena (Lillo 120), pero es también una novela auténticamente transnacional. Según el propio autor la novela está inspirada en la cultura de memoria autocrítica y auto-reflexiva que se estaba desarrollando en Alemania durante los años 1990, país donde el autor estaba viviendo en ese momento (Cruz Suárez 261), y este hecho se tematiza también directamente en el texto a través de la ciudanía e identidad transnacional de la protagonista, Laura, refugiada chilena en Berlín. Laura desempeñaba a la hora del golpe de estado en 1973 la función de jueza en una ciudad ficticia, Pampa 
Hundida, en el medio del desierto de Atacama en Chile. Simpatizaba con el gobierno de Allende, pero como representante del sistema jurídico se vio involucrada en un proceso sumario del régimen (Franz 149-54), y se sintió en parte responsable por la ejecución de 15 presos, ejecuciones injustas pero legales según las leyes vigentes durante la situación de emergencia después del golpe; y además sentía que compartía esta culpabilidad con el médico de la ciudad a quién los militares obligaron a certificar las defunciones y con el cura a quién obligaron a absolver a los convictos.

Poco después de haber llegado a la ciudad, el mayor Cáceres, máxima autoridad del poder militar local, toma en secuestro la figura de la patrona de Pampa Hundida, que, aparte de ser un símbolo religioso también es la fuente más importante de ingresos debido a la cantidad de feligreses y penitentes que cada año peregrinan a la ciudad. Representantes de las autoridades civiles acuden a la joven jueza para pedirle al mayor soltar su "preso" y dejar las ejecuciones, pero el mayor se niega y se impone físicamente a Laura, y le propone un "pacto". El pacto consiste en la promesa de dejar en libertad a uno de los condenados a muerte cada vez que Laura se presente en su casa y se deje someter al acoso sexual del mayor. Laura acepta el pacto, pero cuando al final se da cuenta de que Cáceres no ha cumplido con su parte del acuerdo y ha seguido matando, Laura se enfrenta con él una noche en medio del desierto. Sale profundamente herida y traumatizada.

Después de padecer un período largo de recuperación psíquica Laura emigra a Alemania con la intención de dejarlo todo atrás, pero cuando su hija, el resultado la relación sexual con el mayor - y crecida en Alemania_, veinte años después le pregunta por escrito "¿dónde estuviste tú, mamá, cuando todo esto pasó en la ciudad de tu jurisdicción?” (Franz 12), tiene que volver sobre el pasado. Y lo hace a través de la escritura primero. Escribe una larga carta a su hija, y la misma escritura tiene, según Mario Lillo, la función de un ejercicio traumático (Franz 131) que le permite re-enganchar el pasado con el presente. A través de la escritura se da cuenta de los límites de las letras — como catedrática de filosofía también se ha escondido detrás de las letras durante los 20 años de exiliada - y toma la decisión de volver a Pampa Hundida.

Temáticamente la novela trata de la culpa de esta mujer que en contra su convicción política se ve involucrada en crímenes contra la humanidad, llevada por una atracción oscura. Desde el principio cuando los militares entraron en la ciudad, Laura se sintió atraída y fascinada por el poderoso mayor Cáceres, y su sentido de culpabilidad está relacionado con esta atracción que deconstruye toda distinción fácil entre víctima y victimario y su homologación con las categorías morales del bien y del mal. Laura es a la vez víctima y verdugo, y el paisaje que rodea a Pampa Hundida, el desierto de Atacama, llega a simbolizar la relación seca y estéril de la sociedad chilena con su propia historia, causada por el veneno de este sentimiento de culpabilidad colectiva.

La carta que escribe a su hija es a la vez escritura terapéutica y un acto de pedir perdón que se dirige tanto a la hija como a la opinión pública a través del lector. Según su propia auto-diagnosis Laura ha padecido del síndrome de Estocolmo (Franz 378), y leída según este marco de interpretación la novela puede entenderse como formando parte del paradigma del discurso de la memoria cosmopolita del Holocausto. Y efectivamente, la pregunta de la hija Claudia, ¿Dónde estuviste tú, mama?, se produce como una consecuencia combinada de dos viajes que hace Claudia, el primero al campo de concentración Sachsenhausen en los alrededores de Berlín (Franz 49) y la segunda a 
Pampa Hundida en Chile donde su madre 20 años antes estaba viviendo su propio 'Holocausto'.

La novela invita a lecturas como por ejemplo la historia sobre los efectos traumáticos de la violencia, tal como propone Mario Lillo, o como una novela cosmopolita de retorno del exilio tal como lo hacen Gutiérrez Mouat o Fernando Rosenberg (Gutiérrez Mouat 30; Rosenberg). Según estas últimas lecturas lo interesante de la novela radica en la recuperación de la memoria y la verdad por parte de las víctimas, que saben aplicar los valores democráticos y los derechos humanos aprendidos durante el exilio a las experiencias nacionales del pasado, mientras la "maldad" y la violencia del poder queda relegada a la tradición ancestral. Y esta lectura parece tener fundamento en el texto, que en largos pasajes contribuye a la mistificación del miedo y de la maldad:

Ese silencio de la ciudad santuaria ante la muerte no sólo sonaba a aplauso [...] sino también a algo más que empecé a sospechar [...]. Ese silencio también sonaba al receso de una oración, a la expectativa de un sacrificio, a la muda señal de respeto ante un ritual antiguo que estuvo en las mismas fundaciones de la ciudad santuario y que jamás se había ido del todo, sino que sólo se había "retirado": a las sierras de la cordillera, a las cimas barrida por el viento helado en las cuales dormían su sueño de siglos otros dioses, los de párpados momificados bajo los altares abandonados. Los dioses de antes, devueltos al seno de la diosa originaria (Ishtar, Cibeles, Pachamama) que los había engendrado y devorado a todos. (Franz 84)

En este párrafo el miedo, el silencio y la muerte se vinculan tanto con el paisaje y los elementos naturales como con los comienzos históricos de las civilizaciones globales en una mitificación de la maldad como una fuerza mística. Aquí no se trata de buscar, desvelar o explicar los mecanismos políticos y sociales que llevan a personas normales a torturar e incluso a matar como una actividad trivial y cotidiana. Pero en otro capítulo sí aparece este tipo de reflexiones. En el capítulo donde Laura se encuentra con un joven abogado que quiere denunciar al mayor Cáceres, aparece lo siguiente:

Laura concordaba: el muchacho se habia acertado, sus hechos particulares calzaban y, sin embargo, el dibujo general era otra máscara, no era el rostro del pasado que ella conoció. ¿Por qué? Quizás porque la voluntad y la sed de verdad del joven justiciero lo deformaban. La voluntad de saber lo que no puede saberse, de explicarse lo inexplicable. Saber y explicarse, por ejemplo, la normalidad que rodeó a lo perverso. No que lo perverso se haya vuelto normal, eso sería mala memoria o mala literatura. Sino explicarse y saber que las vidas normales siguieron sus cursos normales, mientras lo extraordinario ocurría. (Franz $94)^{1}$

Aquí conviene un comentario sobre la estructura narrativa de la novela. El discurso cambia de forma regular entre capítulos que reproducen la carta que Laura escribe a su hija en respuesta a su pregunta anteriormente citada (primera cita) y capítulos narrados por un narrador - por lo visto extradiegético- que Mario Lillo considera un representante de la comunidad local chilena (Lillo 122). En el epílogo este narrador se revela como el antiguo marido de Laura, llamado Mario. Eso quiere decir que la primera cita refleja la manera en que Laura antes del viaje de regreso está pensando sobre el pasado, transmitida a través de su propia letra, mientras la segunda cita es estilo indirecto libre de los pensamientos de Laura cuando está escuchando al joven abogado justo después

\footnotetext{
${ }^{1}$ La letra en cursiva indica que el texto forma parte de la carta que Laura escribió a su hija.
} 
de su llegada a Pampa Hundida, traducidos a través del discurso literario del narrador/autor Mario. Pero no sólo eso. La segunda cita también contiene una reflexión meta-literaria y meta-teórica que hace pensar que es la voz del autor empírico, Carlos Franz, que se mezcla en el discurso, aunque el ex marido Mario en su juventud tuviera ambiciones literarias y sea el presunto narrador de la novela.

Esta distinción entre una mitificación del mal que pertenece al momento anterior del viaje de regreso y el interés por la banalización del mal en sentido sociológico que emerge como resultado de la vuelta al lugar del crimen y la memoria, queda desde luego desmentida por la repetición de la referencia a los dioses ancestrales - Ishtar, Cibeles, Pachamama- dentro del discurso novelesco de Mario narrador (Franz 121, 125).

En las primeras páginas de la carta que Laura escribe a su hija, intenta explicar la atracción erótica-corporal que sintió por el comandante Cáceres desde el primer momento que lo vio. El comandante tuvo a su caballo encerrado en un remolque de un jeep cuando los militares vinieron a Pampa Hundida en 1973 (Franz 50), y el poder del comandante, que emanaba de su persona a través de la forma en que logró dominar el caballo que pateaba y bufaba, ansiando salir del remolque, fascinó a Laura. Ella, por su parte, se identificó con el caballo que se rebelaba como "otra cosa dentro de mí misma" (Franz 128). Laura era consciente de la ambigüedad que sentía frente al comandante, una tensión entre atracción erótica y repulsión política, que, por extensión sinecdóquica, se puede aplicar al sistema político. Dice Laura:

El afecto del rehén por su captor, el amor de la víctima por su verdugo [...] [L]a justicia que ama y necesita el poder, a pesar de que éste la viola constantemente - la viola porque está en su naturaleza hacerlo. El amor social, es deseo del bien para las sociedades, signado por esa fatalidad originaria [...]: no es posible hacer justicia sin tener poder y una vez que se tiene poder éste tiende naturalmente a la injusticia, como el caballo a mascar el freno y desbocarse, o el amor a llamar al que no puede mencionarse... (Franz 378)

En este párrafo el plano mítico-erótico penetra el plano socio-político y convierte la transformación política de la sociedad chilena de Pinochet en una tragedia inevitable. Las tensiones entre razón y deseo, entre ley y poder, quedan subsumidas debajo de la relación entre el principio platónico y el principio dionisíaco como principios ancestrales y míticos. De esa forma quedan despolitizados los procesos sociales y políticos particulares que el ejército empleó para aplastar cualquier resistencia u oposición al régimen político después del golpe. Debido a esta mitificación y universalización del mal consideramos que El desierto pertenece a la modalidad "Eichmann está dentro de todos nosotros" de Torgovnick.

\section{Arturo Fontaine: La vida doble (2010)}

La novela La vida doble de Arturo Fontaine narra el testimonio de una mujer chilena también refugiada en Europa después de haber colaborado con los militares después del golpe en 1973. En el momento de contar la mujer se está muriendo de un cáncer en Estocolmo mientras le cuenta su historia a un escritor anónimo que se parece mucho al autor real, Arturo Fontaine. La mujer, que pide al escritor que la llame Lorena, es de descendencia de la clase media acomodada, estudió de joven literatura francesa y vivía de dar clases de francés en Santiago de Chile. Desde su adolescencia se rebeló 
contra los negocios de su padre, y llegó a militar en un grupo de la izquierda radical (ficticio) llamado 'Hacha roja', que a partir de 1973 participaba en la lucha armada contra el régimen de Pinochet. En esta época su nombre de guerra fue Irene. Durante una acción armada contra una oficina de cambio fue capturada y sometida a tortura, pero supo aguantar las necesarias cinco horas antes de que delató a los de su grupo ${ }^{2}$. Después de unos meses fue puesta en libertad, pero cuando la inteligencia descubrió que tenía a una hija viviendo en la casa de su madre, volvieron a detenerla y amenazaron con secuestrarle a la niña. Sus compañeros de 'Hacha roja' ya le habían ordenado mandar a la hija a vivir en un asilo de niños refugiados en Cuba como precaución, pero Irene se había resistido por razones sentimentales. En este momento, cuando los verdugos le amenazaron con la niña, no sólo delató a sus compañeros, sino que pasó al otro lado de forma activa. Se convirtió en traidora. Muchos años después dice al escritor en Estocolmo:

Fue una traición, pero una traición sincera. Quiero decirte: mi traición provenía de la verdad. Pienso ahora que, en el fondo, ya no quería seguir con esa vida de combatiente clandestina, no quería seguir viviendo a salto de mata siempre a punto de ser descubierta, no tenía esperanza porque había perdido la fe en el pueblo, en su corazón revolucionario. (Fontaine 130)

Que la traición fuera una traición sincera implicaba que la Irene de la 'Hacha roja' se convirtiera en La Cubanita, y que no sólo delatara a sus excompañeros y sus refugios, sino que se enrolara en el cuerpo policial, lo que en la realidad equivaldría a la DINA, y participara en las captaciones, interrogatorios y sesiones de tortura de los mismos. La tortura que sufrió como Irene fue demoledora e incomparable tanto en intensidad como en duración - como las violaciones que sufrió Laura en El desierto-, y es probable que una amenaza a su hijo o hija podría romper las últimas gotas de resistencia a cualquier persona. Pero cuando no sólo se deja vencer en sentido físico, sino que se enamora del agente policial llamado El Flaco, parece que volvamos al mismo registro de fuerzas opuestas que podíamos observar en El Desierto, es decir, la tensión entre repugnancia moral y atracción sexual como fuerzas individuales y existenciales. La diferencia es que, aunque Laura en El Desierto reconozca el contraste en su interior entre deseo y razón, se mantiene fiel a su postura política y sus ideales éticos y morales hasta el final. En cambio, Irene se deja transformar en La Cubanita:

[El Flaco] me regaló un montón de cosas. Yo despreciaba estas ropas [...] No calzaban con el espíritu acerado que exigía nuestra lucha. Pero ahora quería verme bonita $[\ldots]$ Nunca en mis años de combatiente clandestina me habría puesto ropa así. Toda esa austeridad nuestra, te digo, la mandé al carajo. ¿Me estaría volviendo medio puta? ¿Yo? ¿La niña tímida educada por las monjas? (Fontaine 148)

En la vida civil Irene sigue siendo la Irene de siempre que mantiene sus contactos en los círculos subversivos, pero encarnando la figura de La Cubanita llega a ser una mujer promiscua, que goza del alcohol y de las drogas, e incluso se deja prostituir de forma voluntaria al servicio de los amigos de El Flaco. Este cambio de personalidad y de

\footnotetext{
${ }^{2}$ Cuando una persona era detenida por la policía era necesario que resistiera la tortura durante un mínimo de cinco horas antes de delatar a otros para que sus compañeros pudieran escaparse.
} 
postura sorprendente e incluso provocador para el lector está, no obstante, basado en hechos reales. Se conocen como mínimo tres casos diferentes de mujeres pertenecientes a la oposición política que no sólo no sabían resistir la tortura y delataron a sus compañeros, sino que llegaron en una fase posterior a colaborar directamente con la DINA como agentes contratadas. Arturo Fontaine escribe en un apartado al final sobre sus fuentes lo siguiente: "Aunque los personajes y episodios de esta novela son ficticios, el autor tomó como punto de partida hechos e historias reales. Aparte de conversar con diversos protagonistas y testigos de la época, hizo uso de la siguiente bibliografía documental", y sigue una larga lista de nombres y títulos.

La más famosa de sus modelos es probablemente Marcia Alejandra Merino, dirigente del MIR con la tapa La Flaca Alejandra, que fue detenida el primero de mayo de 1974. Sostuvo al principio la tortura y la soltaron, pero volvieron a detenerla y torturarla, y fue esta segunda vez cuando se rindió, igual que la Irene de la novela. Y como Irene colaboró en la identificación de sus excompañeros y se dejó enrolar como agente en DINA. Después de la transición a la democracia en 1990 se arrepintió, colaboró como testigo en la comisión Rettig (Testimonio) y publicó el libro Mi verdad... Más allá del horror; yo acuso (1993), libro que figura en la lista de fuentes de Fontaine. La Flaca también participó en el documental con su propio nombre, rodado por Carmen Castillo, que también figura en la lista (Castillo). Otro caso real sería Luz Arce, una mujer joven y militante del partido socialista, a la que también detuvieron y torturaron dos veces. La segunda vez torturaron también a su hermano ante de sus ojos y amenazaron con secuestrarle a su hijo, con lo cual se quebró. Luz Arce no sólo delató a sus compañeros, sino cambió de lado y asistió a sesiones de tortura, e incluso llegó a ser jefe de sección de la DINA (posteriormente CNI) y profesora titular de la Escuela Nacional de Inteligencia. Igual que Irene en la novela se enamora de su adversario, el general Rolf Wenderoth, para quién trabaja como secretaria y con el que vive una relación amorosa. A partir de la transición se arrepiente igual que La Flaca, colabora como testigo en la comisión Rettig y publica el libro El infierno en 1993, un texto autobiográfico y confesional. En una re-lectura de este libro, María Eugenia Escobar destaca, basándose teóricamente en Michel Foucault, cómo la amalgama de discursos del texto, entre ellos el discurso religioso-confesional, revela la débil posición del yo, o incluso la aniquilación de la propia subjetividad:

En nuestro acercamiento a este texto nos hemos encontrado con un tramado de unidades discursivas, que muchas veces se cruzan, aparecen de modo solapado o, bien son, por el contrario, absolutamente premeditadas y explícitas [...] Todos estos discursos van mostrando una forma específica de mostrar ciertos poderes, los que mediante un denso tramado, van conduciendo inexorablemente a la anulación del "yo". (Escobar)

Esta posición débil del yo en el texto será importante a la hora de interpretar la forma a través de la cual Lorena cuenta su propia historia.

La tercera mujer real que queda detrás de la figura ficticia de la protagonista es María Alicia Uribe con el nombre de guerra Carola. Carola fue también dirigente del MIR como La Flaca, traicionó también a sus compañeros e ingresó en la DINA como agente, pero en contraste con La Flaca y Luz Arce no se arrepintió nunca y se negó a colaborar con las fuerzas de la justicia transicional. En la página web de La memoria viva ponen: "Su historia es la más desconocida y desconcertante sobre el tema de la delación en el gobierno militar y, por ese motivo, estuvo entre las fuentes de inspiración para 
construir a Irene, el personaje principal de la novela La Vida Doble, de Arturo Fontaine" (Memoria viva sobre Carola). Carola fue en 2014 acusada de forma jurídica por ser la responsable de la muerte de dos dirigentes del MIR, Carrasco Vásquez y de Humberto Menenteau Aceituno. Fue sometido a proceso en 2015, y en el momento de la redacción de este texto todavía no se conoce el resultado del juicio.

Fontaine crea la voz de su personaje como una amalgama de estas tres mujeres reales, pero añade a través de la ficción también su propia interpretación de la figura. En un estudio de la relación entre realidad y ficción de esta novela Peris Blanes se sirve del concepto del "pacto ambiguo", elaborado por Manuel Alberca dentro del campo del estudio de la autoficción. El pacto ambiguo ubica lo narrado en el ámbito de la ficción, a la vez que se tiñe de la autenticidad de los testimonios de los supervivientes reales (Peris Blanes 54). En la novela las coincidencias concretas entre frases del testimonio de Luz Arce y algunas descripciones de tortura encontradas en la novela dan este tipo de autenticidad, y hay además coincidencias visibles entre los sucesos vividos e imaginados. Como Carola, Lorena no es una mujer arrepentida, y sólo acepta la entrevista del escritor a cambio de una compensación de 30.000 dólares en efectivo que quiere dejar como una herencia a su hija. Y como Luz Arce es una mujer con una sensación débil de su propio yo. El discurso de memoria está lleno de citas literarias y de canciones populares como un mosaico detrás del cual se esconde el sujeto narrativo, siendo la cita más simbólica y significativa la de Rimbaud: 'Je est un autre' ("Soy otra”, Fontaine 84). Además, Lorena insiste una y otra vez en el hecho de que su discurso no sea uniforme y coherente, y en la última mitad del libro, después de que haya contado su rendición, dice a menudo: "me contradigo", haciendo referencia a las dos identidades y las dos visiones del mundo que se desprenden de ellas (Fontaine 158, 166). Y como una forma de resumen de esta posición partida y vaciada de su propio sujeto, dice en la última página de la novela al escritor:

Te llevas tu bloc bien lleno... ¿Para mis citas? Ja, ja! Mi yo es un hoyo lleno de puras citas... Ja, ja! Lo que te cuento, insisto, no te sirve. Para tu novela, digo. Olvida esta Lorena. Una buena novela deja entreabierta la esperanza. Yo no. ¿Sabes quién es la mujer que te habla? Soy una pregunta para ti. Soy tu Lorena, nada más. (Fontaine 300)

La trama de la novela ofrece como mínimo tres marcos diferentes de interpretación que pueden explicar este desarrollo de la protagonista, y será a través de la examinación de estos marcos que podemos juzgar el modo ético-político que informa la narración. El primer marco de interpretación podría basarse en el argumento del síndrome de Estocolmo que, según el propio Carlos Franz en una reseña de la novela, sería una explicación demasiado simple y obvia. De acuerdo con la teoría de este síndrome, las víctimas de un agravio como un secuestro pueden llegar a simpatizar con la causa de los victimarios, y según testimonios de víctimas de tortura, los verdugos aparecen como más grandes, más poderosos e incluso más bellos de lo que en realidad son (Testimonio de La Flaca Alejandra ante la Comisión Rettig). Esta interpretación se mantiene dentro de un marco que considera a Lorena básicamente como víctima, y el hecho de que Lorena se muera en Estocolmo simboliza que el personaje no logró nunca salir del trance de este síndrome. 


\section{Factores socio-políticos}

El segundo marco de interpretación pondría su énfasis en los factores socio-políticos. Dice Peris Blanes sobre el uso de tortura en la estrategia del régimen militar:

En el interior de los centros de tortura, uno de los objetivos básicos había sido quebrar las identidades sociales, aislando a los individuos y volviendo a los militantes contra sus propios compañeros, quebrando todo tipo de solidaridad posible. Ese no era, desde luego, un aspecto secundario de la violencia extrema, sino una de sus aspiraciones fundamentales. (Peris Blanes 50)

En la novela, narrada de forma autobiográfica por una narradora no arrepentida, no podemos como lectores esperar un análisis explícito de esta estrategia. Sería romper la lógica narrativa — sería mala literatura- En cambio, tenemos como lectores que analizar los hechos narrados como síntomas que revelan la estrategia militar que queda detrás. Para lograr el objetivo de quebrar la identidad social de la clase obrera y el movimiento socialista en Chile, fue necesario destruir toda esperanza en una revolución socialista. Y para lograr el objetivo de destruir la integridad personal e individual de sus opositores, el régimen abrió unos marcos espacio-temporales de excepción que permitían el uso ilimitado de la violencia y la tortura. Vamos a ver cómo Lorena explica este proceso desde su experiencia subjetiva. En primer lugar es la falta de esperanza en la conquista de una sociedad justa y sin desigualdad social, la que le permite a Irene cambiar el sentimiento de solidaridad que tuvo con sus excompañeros con desprecio y hasta odio. Dice Lorena:

Esa sociedad de iguales en la que creíamos, no existiría nunca. El país de antes había muerto. Lo mataron [...] Era cosa de ver a los obreros. Antes alegres y apiñados adentro de los camiones, levantando el puño [...] Ahora saliendo del Mall, los puños abajo, cargando de bolsas y frustraciones de vuelta a casa. (Fontaine 130)

El golpe militar y la destrucción posterior de cualquier organización legítima obrera o sindical cambió de un día a otro el panorama político, y este cambio tuvo un afecto directo e inmediato en la manera en que la izquierda militante podría identificarse a sí misma. Dice Lorena:

En lugar de ser héroes estábamos destinados a ser unos extremistas desubicados y medio inventados por los militares, unos ingenuos que dan lástima. La vanguardia de combatientes que inaugura un mundo nuevo se convertiría en un rebaño de víctimas, la punta de lanza de guerrilleros y héroes pasaría a ser un hato de corderos sacrificados. (Fontaine 123)

El cambio en la relación de fuerzas sociales producido por el golpe militar establece el discurso de la derecha política como hegemónico, lo cual tiende a cambiar la perspectiva con la que la oposición se contempla a sí misma. El cambio en la relación de fuerzas sociales significa que Irene aplica la visión del 'otro' a su propio grupo, y lo que ve no es un grupo de héroes sino un lamentable grupo de "tontos útiles" (Fontaine 133). En palabras del sociólogo británico Richard Jenkins la categorización negativa 
exterior vence a la auto-interpretación positiva como resultado de un cambio significativo entre las fuerzas políticas de la sociedad en cuestión (Jenkins).

Una vez que se haya puesto en cuestión la identidad social del grupo al cual pertenece el sujeto, hace falta preparar el cambio de personalidad, lo cual se consigue a través de la tortura. Lorena cuenta en el segundo capítulo la experiencia de la tortura la primera vez que fue capturada:

El amo logrará ir doblegándome como si llegase a ser un animalito suyo. El rostro que no puedes ver empieza a ser un todopoderoso, mi aterrador deus absconditus, mi dios escondido [...] Uno se puede morir ahí adentro de puro agotamiento, de puro desaliento, de pura soledad. Es una vida moribunda la que vivo. No hace falta que te maten. Tú te vas alejando hasta dejarte a ti misma, y eso es morir. (Fontaine 16)

La tortura no se describe con visión exterior, sino a través de la reproducción de una visión interior de pensamientos y sentimientos que revelan este estado de "nuda vida" en sentido de Giorgio Agamben. Es la aniquilación de todos los aspectos de la vida humana aparte de la vida biológica, o sea la vida tratada como materia (Agamben). Como es bien sabido, el lugar paradigmático para la reducción al ser humano a esta forma de nuda vida es para Agamben el estado de excepción del campo de exterminio nazi (4), y Lorena en La vida doble también da testimonio de que son unas condiciones sociales y políticas parecidas las que son necesarias para poder desatar esa violencia ilimitada sobre un ser humano:

Establecido el lugar de la impunidad delimitada [...] se desata en el buen padre, en la hija de familia ese monstruo que llevamos dentro, esa fiera que se ceba con la carne humana. Pero para que eso ocurra tiene que haber una orden que tú acatas y te vuelve inocente. La pertenencia a la institución [...] la disciplina, es lo que permite ese traslado de la culpa al de arriba, al superior en la jerarquía. (Fontaine 140)

En esta cita la narradora tiende hacia una explicación del mal que busca su razón de ser en los sistemas totalitarios, es decir, en sistemas que favorecen la disciplina y la obediencia en consonancia con el análisis de "la banalidad del mal" que hizo Hannah Arendt del caso de Eichmann. Pero aunque mencione la inclinación hacia el mal como una disposición interior en el ser humano, "ese monstruo que llevamos dentro", no universaliza el mal como una adoración del poder de la especie humana como en la novela de Franz, sino busca las precondiciones de las atrocidades del pasado en los factores socio-culturales del contexto histórico. En este sentido podemos afirmar que la novela representa la versión "Cualquier de nosotros podríamos ser Eichmann" de Torgovnick.

\section{Mitificación intertextual}

El tercer marco de interpretación que ofrece la novela para explicar la conversión no sólo de postura y filiación, sino también el cambio de personalidad que sufre Irene en el proceso de conversión a Lorena, lo podemos buscar al nivel mitológico a través de algunas referencias intertextuales. Cuando Lorena cuenta la experiencia que tuvo como Irene de delatar, dice que fue un "pacto fáustico": 
Hay un vértigo en la delación. Literalmente uno se da la vuelta. Y confiesa y llora y cuenta y llora nombres, fechas, lugares marchitos [...] Ha sido un pacto fáustico. Y todavía no sospechas lo que significa esa expresión, "haber vendido tu alma al diablo". Un deus absconditus se quedó con todo lo que podrás ser, un Mefistófeles celoso, cuyo deseo es violento y total. Hay algo mañosamente atractivo en esa muerte. Debo nacer de nuevo para el Flaco, para el Gato, soy una mujer nueva, "la Cubanita"... (Fontaine 155)

De acuerdo con esta referencia, al delatar a sus compañeros, Irene también vende a su alma. Y como Lorena se refiere repetidas veces al significado de la traición según el sentido que le da Dante, la novela nos invita a interpretar el pacto fáustico en este contexto. Cuando Lorena, por ejemplo, con desprecio explica que el libro que el escritor pretende crear nunca logrará comunicar la esencia de la experiencia vivida, dice: "Es inútil. Quedará la fábula edificante con su moraleja, quedará la cáscara de los hechos [...] Pero lo que les dio un sentido, lo que los hizo humanos, muere con nosotros" (Fontaine 39). Y la razón por la cual el "alma bella"3 del escritor no llegará nunca a entender, es porque la traición, según Dante, es el pecado máximo, vinculado con el último escalón del infierno:

Fíjate que cuando Dante llega al fondo del Infierno encuentra al Demonio llorando. No por eso deja de ser el Demonio, no por eso se arrepiente. Si lo hubiera hecho, estaría en el Purgatorio, tendría esperanza. El demonio no se arrepiente y sin embargo llora, llora sin esperanza [...] Castiga a los que inspiró y han seguido sus pasos, los castiga día y noche mientras es castigado. Es el traidor insuperable (Fontaine 40)

Según Dante, el traidor ha pecado de una forma tan fundamental que ha perdido toda esperanza, con lo cual ni siquiera se puede arrepentir. Dice el propio Fontaine en una entrevista publicada en septiembre de 2010:

Para Dante, la traición era peor y estaba asociada con el propio demonio: quién traicionaba perdía su alma, que viajaba al infierno y era derechamente el diablo quien se apoderaba de su cuerpo mientras el traidor vivía en tierra. (Vásquez)

Pero en nuestro caso es importante destacar la relación que la novela establece entre esta visión mitológica de la traición en Dante y la falta de toda esperanza política y social que, como acabamos de ver, está directamente vinculada con la implantación de un nuevo régimen ideológico, hegemónico a partir del golpe en 1973. Dice Lorena: "En la puerta del Infierno de Dante está escrito: Deja toda esperanza tú que entras. Yo vivía así. Había perdido toda esperanza y todavía no moría. En este estado de abatimiento vería yo a muchos" (Fontaine 152). La figura del hombre reducido a la nuda vida, el muerto vivo sin alma, llega a ser una metáfora para Lorena, que, a través de las referencias a Dante y del contraste con el alma bella de Goethe, se llena con un significado mitológico que no contradice sino que complementa la contextualización polí-

\footnotetext{
${ }^{3}$ Trazando la historia del concepto de la "alma bella" desde Platón y Plotino, pasando por Schiller y Goethe a Hegel, Mario Lillo hace una interpretación de su uso aquí como una metonimia de la sociedad chilena que en la actualidad intenta elaborar la tragedia post 1973, manteniéndola a una distancia confortable (Lillo 180-82).
} 
tico y social de la banalidad del mal. Si para Carlos Franz los mitos sirvieron para universalizar el mal como una disposición humana y ahistórica, para Arturo Fontaine el significado mitológico se añade al marco socio-político de interpretación y aporta otra perspectiva más profunda de forma complementaria.

\section{Conclusión}

Ambas novelas focalizan la narración desde la perspectiva de personajes que pertenecen a la zona gris y pueden leerse como dos intentos diferentes de abordar los límites impuestos por la perspectiva más extendida en las novelas memorialistas en español, la de la víctima. En El desierto las tensiones entre razón y deseo, entre ley y poder, quedan subsumidas bajo la relación entre el principio platónico y el principio dionisíaco como principios ancestrales y míticos, y las fuerzas del mal quedan interiorizadas y universalizadas como disposiciones humanas. En este sentido es coherente la interpretación que hace la novela de las reacciones del ser humano frente a las cuestiones éticas de máxima importancia con la modalidad que María Torgovnick llama "Eichmann está en todos nosotros". En cambio, La doble vida, según la lectura que se ha hecho en este artículo, puede interpretarse como ejemplo del modo "todos podemos ser Eichmann". Peris Blanes no estaría de acuerdo porque considera que el hecho de que Fontaine desvincule el tema de la violencia de la implantación del sistema económico del neoliberalismo en Chile produce una despolitización de la violencia sistemática del régimen, con lo cual la conversión de Irene en Lorena también en este caso se explica acudiendo a causas psicológicas e individuales. Según la lectura aquí propuesta la novela efectivamente ofrece todos los elementos necesarios para comprender el uso estratégico de la violencia del régimen, pero los motivos de dicha violencia se describen de forma subjetiva en función de cómo son padecidos por la narradora. Es decir, la focalización radical en la perspectiva de la traidora obliga al lector a leer el discurso monológico como un síntoma de lo padecido por la estrategia del régimen. Resultaría artificial, según esta lectura, que la misma narradora explicase de forma clara y crítica la finalidad de esta estrategia estatal, si ella misma era y sigue siendo afectada, o sea, victimizada por ella.

Podemos por lo tanto concluir que El desierto, a pesar de sus meta-reflexiones y multiperspectivismo, no contribuye al análisis y comprensión de los procesos sociales y políticos que convierten a personas normales en criminales responsables de crímenes de lesa humanidad. Contribuye, en cambio, a la despolitización de los procesos sociales y políticos particulares que el ejército empleó para aplastar la oposición al régimen después del golpe. La transformación autoritaria de la sociedad chilena se convierte por lo tanto en una tragedia inevitable y, en este sentido, la novela se inscribe en el modo ético-político cosmopolita. En cambio, La otra vida permite al lector, a través de la focalización subjetiva de Lorena, no sólo reconstruir los procesos sociales y políticos que impuso el régimen, sino también comprender los mecanismos psicosociales que llevaron a esta mujer a convertirse en perpetradora. $\mathrm{Y}$ al insistir en la búsqueda del 'mal' mediante el entendimiento de las condiciones y procesos socio-políticos, la novela no sólo reabre la discusión política sobre el pasado, sino que plantea también de forma agonista la relación entre este pasado y la sociedad chilena actual. 


\section{Bibliografía}

Agamben, Giorgio. Homo sacer. Sovereign Power and Bare Life. Stanford: Stanford University Press, 2004.

Arendt, Hannah. Eichmann en Jerusalén. En estudio sobre la banalidad del mal. Barcelona: Lumen, [1963] 2003.

Castillo, Carmen. La Flaca Alejandra. Francia/Chile/Reino Unido. 1994. Documental. Web. 2 julio 2018.

Cento Bull, Anna y Hans Lauge Hansen. "On Agonistic Memory.” Memory Studies 9.4 (2016): 390-404.

Crownshaw, Richard. "Perpetrator Fiction and Transcultural Memory." Parallax 17.4 (2011): 75-89.

Cruz Suárez, Juan Carlos. "Justicia y culpabilidad. El desierto de Carlos Franz como paradigma crítico-memorialista de una transición insuficiente en Chile". Conflictos de la memoria/Memoria de los conflictos. Modelos narrativos de la memoria intergeneracional en España e Italia. Ed. Hans Lauge Hansen y Leonardo Cecchini. Copenhague: Museum Tusculanum Press, 2015. 255-272.

Eaglestone, Robert. "Avoiding Evil in Perpetrator Fiction." Holocaust Studies 17.11 (2011): 13-26.

Escobar, María Eugenia. "El infierno, de Luz Arce: Un tramado de unidades discursivas.” Cyber Humanitatis 52 (2009). Web. 2 julio 2018.

Fontaine, Arturo. La vida doble. Alicante: Biblioteca Virtual Miguel de Cervantes, 2011.

Franz, Carlos. El desierto. Buenos Aires: Editorial Sudamericana, 2005.

Gómez López-Quiñones, Antonio. “A Secret Agreement. The Historical Memory Debate and the Limits of Recognition.” Hispanic Issues Online 11 (2012). Web. 2 julio 2018.

Gutiérrez Mouat, Ricardo. "La novela post-exílica de repatriación.” Hispamérica 40.120 (2011): 27-35.

Jenkins, Richard. "Categorization: Identity, Social Process and Epistemology." Current Sociology 48.3 (2000): 8-25.

Levi, Primo. The Drowned and the Saved. London: Michael Joseph, 1988.

Levy, Daniel and Natan Sznaider. "Memory Unbound: The Holocaust and the Formation of Cosmopolitan Memory." European Journal of Social Theory 5.1 (2002): 87106.

Levy, Daniel y Natan Sznaider. The Holocaust and Memory in the Global Age. Philadelphia: Temple University Press, 2006.

Lillo, Mario. Silencio, trauma y esperanza. Novelas chilenas de la dictadura 1977-2010. Santiago: Ediciones Universidad Católica de Chile, 2013. 
Peris Blanes, Jaume. "Contradicciones de la memoria. Ficcionalización del testimonio y figuración de la traición en La vida doble (Arturo Fontaine, 2010)." Les Ateliers du SAL 3 (2013): 49-63. Web. 2 julio 2018.

Pfeiffer, Alice. "El proceso de justicia transicional en Chile desde las relaciones de poder: La dimensión política jurisprudencial.” Revista Historia y Justicia 3 (2014): 256-284.

Rosenberg, Fernando J. "Derecho humanos, comisiones de verdad, y nuevas ficciones globales". Revista de crítica literaria latinoamericana 35.69 (2009): 91-114.

Torgovnick, Marianna. War Complex: World War II in Our Time. Chicago: University of Chicago Press, 2005.

Vásquez, Juan Gabriel y Arturto Fontaine. "La Vida Doble. Arturo Fontaine en conversación con Juan Gabriel Vásquez.” Hay Festival (2013). Web. 2 julio 2018.

\section{Páginas web}

Testimonio de La Flaca Alejandra. Web. 2 julio 2018. http:/ flacaalejandra.blogspot.dk/2012/12/informe-rettig.html

Marcia Alejandra Evelyn Merino Vega, Agente DINA/CNI/DINA, Alias: "la flaca Alejandra". (www.memoriaviva.com). Web. 2 julio 2018.

http://www.memoriaviva.com/criminales/criminales_m/merino_varga_marcia_alejandra.htm

Luz, Arce Sandoval, Agente DINA/CNI, Alias: "Mariana del Carmen Burgos Jiménez"” (www.memoriaviva.com). Web. 2 julio 2018.

http://www.memoriaviva.com/criminales/criminales_a/arce_sandoval_luz.htm

María Alicia Uribe Gómez, Agente DINA/CNI, Chapa: "Carola" (www.memoriaviva.com). Web. 2 julio 2018.

http://www.memoriaviva.com/criminales/criminales_u/uribe_gomez_maria_alicia.htm 